Peer-Reviewed Article

ISSN: 2162-3104 Print/ ISSN: 2166-3750 Online

Volume 7, Issue 2 (2017), pp. 329-346

(C) Journal of International Students

http://jistudents.org/

\title{
Student and Staff Perceptions of the International Postgraduate Student Experience: A Qualitative Study of a UK University
}

\author{
Emma L. Bird \\ University of the West of England, Bristol, UK
}

\begin{abstract}
This study aimed to explore student and staff perceptions of academic, personal and social factors influencing the international postgraduate student experience at a UK University. Focus groups were conducted with international students enrolled in a Master in Public Health programme $(n=10)$. An in-depth survey containing open-ended questions was completed by university staff that contribute to postgraduate teaching $(n=12)$. Qualitative data were analysed using Thematic Analysis. Student and staff perceptions of the international postgraduate student experience were broadly similar, although some discrepancies were identified. Five themes emerged: adjustment to academic expectations; adjustment to academic conventions; programme internationalisation; adjustment to the local culture; and, future plans. Findings add to the limited evidence base on the international postgraduate student experience in UK universities.
\end{abstract}

Keywords: Experiences, international students, postgraduate, qualitative research, university staff

In recent years, a growing number of students have chosen to travel abroad to further their education (Healey, 2008; Organisation for Economic Cooperation and Development [OECD], 2008; Russell et al., 2010). Statistical data from the academic year 2013/14 reveals that in the UK alone, over 435,500 international students enrolled onto undergraduate and postgraduate programmes (Higher Education Statistics Agency [HESA], 2014), contributing to almost $14 \%$ of all first-year students and $69 \%$ of all full-time taught postgraduate students (UK Council for International Student Affairs, 2015), and resulting in a boost to the UK economy (DBIS, 2011). It is, 
therefore, apparent that there is a need to better understand and embrace cultural and educational differences within higher education (Seo \& KoroLjungberg, 2005).

The increase in international student numbers has altered the demographic of the UK postgraduate student body and has resulted in larger classroom sizes (Tight, 2004). Evidence of the impact of classroom size on the student experience is well documented, with large class teaching associated with poorer learning outcomes (Ehrenberg et al., 2001), reduced student engagement (Light, 2001), and limited curriculum coverage (Bean, 2001; Hoyt \& Perera, 2000). However, due to increased student numbers and diminishing staff within the Higher Education sector (Higher Education Funding Council for England [HEFCE], 2010), it is predicted that large class sizes will continue in University settings, thus requiring a rethink about how teaching and learning approaches need to adapt to such a large and diverse student body (Maringe \& Sing, 2014).

There is a comprehensive body of literature devoted to exploring the experiences of international students (Ward, Bochner \& Furnham, 2001). A recent critical review identified numerous factors associated with positive learning experiences among international students studying in the UK, such as the opportunity to meet and develop relationships with students from around the world, broadened understanding and improved skills in independent thinking, and improved language skills (Lillyman \& Bennett, 2014). Furthermore, there is growing evidence to suggest that the presence of international students can help to expand the perspectives of UK students and academic staff alike (Kingston \& Forland, 2008; O’Reilly et al., 2013; Wang, 2012).

Despite such promising outcomes there also is a wealth of literature reporting the difficulties that may be faced by international students; such as: difficulty in adapting to academic conventions (e.g., poor understanding of plagiarism) (Wang \& Shan, 2006), stress or confusion relating to alternative teaching and learning styles (Bamford et al., 2002; Durkin, 2003; Kiley, 2003; Kingston \& Forland, 2008), and language difficulties (Sawir, 2005). In addition to academic adjustments, studies have shown that international students can encounter social and personal difficulties including problems in adjusting to the local culture (Bamford et al., 2002), loneliness and isolation (Edwards \& Ran, 2006), and financial struggles (Turcic, 2008). It has also been suggested that the international student experience may be influenced by an individual's prior learning experiences and personal background (Oliver, 2008).

With international students contributing heavily to the UK postgraduate student population, it is perhaps surprising that the majority of research exploring the experiences of international students is somewhat limited to undergraduate students. The literature also tends to focus 
specifically on the experiences of Asian international students ( $\mathrm{Li}$ et al., 2014; Smith \& Khawaja, 2011), primarily due to the fact that the vast majority of international students originate from Asia (Institute of International Education, 2014).

Research exploring university staff perceptions of the international student experience is also relatively unexplored. This is surprising given that university staff are likely to have a reasonable understanding of the experiences international students face, and they may offer a unique insight into specific needs and required support. One qualitative study with university staff revealed that staff held under-developed views about why students struggle to adjust and subsequently withdraw from university, such as the identification of 'typical withdrawers' and 'mature women with families' (Ozga \& Sukhnandan, 1998). However, it could be argued that this study is now out-of-date, given the numerous changes which have occurred in universities in recent years.

More recent research suggests that staff perceptions may be biased by the extensive literature on the experiences of students that withdraw from university, rather than those who persist (Briggs \& Pritchett, 2010). Briggs and Pritchett's study of student and staff perceptions found that staff had a reasonable awareness about the main factors that influence students, but there were areas of discrepancy between student and staff perceptions. For example, staff were found to be ill-informed about the factors relating to student experience which were deemed to "fall outside of their own job remit” (Briggs \& Pritchett, 2010, pp. 13). However, the authors acknowledged that these factors may have been identified, had different university staff been interviewed. Another study conducted by Miles and Leinster (2009) reported findings which were broadly in line with Briggs and Pritchett (2010), suggesting that more work may be needed to encourage staff to better understand the student experience and not simply rely on pre-conceived ideas.

The University of the West of England (UWE), Bristol, is one of the UK's largest Higher Education Institutions (HEI), with over 27,000 students and 3,000 staff. The Masters in Public Health programme at UWE offers students an advanced, contemporary education in public health theory, practice and research. A distinctive feature of the programme is the diversity of the student population. Each year the programme attracts applicants from a wide range of cultural, demographic and professional backgrounds. In the Academic Year 2014-2015, 31 full-time international students enrolled on the programme. Of these, 16 students were native to sub-Saharan Africa, with others originating from Mauritius, Burma, Nepal, India, Bangladesh, Hong Kong, and Pakistan. The programme team consists of twelve academics, with an additional 10 university staff providing dissertation supervision and wider student support (e.g., Subject Librarian). This study 
aimed to identify and reflect upon the key academic, social and personal factors influencing the experience of international students enrolled on a postgraduate programme in the UK.

\section{RESEARCH METHOD}

\section{Sampling and Recruitment}

All international students $(n=31)$ enrolled on the Masters in Public Health programme were invited to participate in this study (Academic Year 2014-15). Previous Masters in Public Health students, based in the UK, were also invited to take part. Students were alerted to the study via an email announcement. Interested students were recruited using a purposive sampling approach. Purposive sampling is sampling method in which researchers use their knowledge about the population of interest to hand pick relevant people to include in the sample to answer the research question. In this case, only international students enrolled on the Public Health program were invited to participate. Students were provided with an information sheet containing an explanation of the nature of the research project and asked to provide active informed consent.

All staff contributors to the program $(n=22)$ were invited via email to complete a short online survey. Staff were provided with an information sheet and asked to complete a consent form prior to participation. Ethical approval was granted by the University Education Department in January 2015.

\section{Data Collection}

Two in-depth semi-structured focus groups took place with students on the University campus. To ensure that all focus group members were given sufficient time to share their thoughts and experiences, the researcher encouraged everyone to participate and prompted where appropriate. Each focus group was conducted during the student lunch hour and lasted approximately 45 minutes. An indicative topic guide based on previous research exploring the academic, personal and social experiences of international students was developed to elicit information (see supplemental materials).

Following student focus groups, an online survey was emailed to Public Health program staff. Staff members were asked to complete the survey in their own time at their own computer, and they were given a deadline of two weeks to return their responses. Staff were asked to report on the extent to which they contribute to the program; to reflect upon how they address the learning needs and interests of international students when developing module content; how they communicate module expectations to students; perceptions of rapport between UK and international students; how they 
encourage class participation; perceptions of the academic, personal and social challenges faced by international students; and, areas for improving the international student experience.

\section{Data Analysis}

Focus group data and free-text survey data were imported into NVivo (QSR International) verbatim, software used to aid qualitative data analysis. Data were explored using Thematic Analysis; a method commonly used for "identifying, analyzing and reporting patterns within data" (Braun \& Clark, 2006, p. 6). The researcher read through the data multiple times to aid familiarization and form initial impressions about the data. Coding and theme development began with consideration of the two main areas for exploration in this study: academic experiences, and personal and social experiences. These pre-defined codes were broad with the main purpose of categorizing information for further examination. The researcher took care not to be restricted by such pre-defined ideas and allowed for unspecified codes and themes to emerge from the data inductively. Initial codes were considered and revised to produce a coding framework. All data were then re-coded according to the framework. To ensure credibility and trustworthiness of the data analysis procedure, relevant quotations from each theme were identified to illustrate and support the findings.

\section{RESULTS}

\section{Participant Characteristics}

Ten international postgraduate students participated in this study (30\% response rate). Of these, 4 were male (40\%) and 6 were female $(60 \%)$. Students were aged between 22 and 34. Students originated from Burma $(n=1)$, Ghana $(n=3)$, Malaysia $(n=1)$, Mauritius $(n=1)$, Nepal $(n=2)$, Senegal $(n=1)$ and Somalia $(n=1)$. The academic background of students was highly diverse, with students holding undergraduate qualifications in subjects including Medicine, Business Administration, Biomedical Science, Law and Economics, and History. Eight students had work experience prior to pursuing the postgraduate course; two students had transferred to postgraduate study directly from undergraduate study. The majority of students had been living in the UK for approximately 8 months, while two had been based in the UK for more than 2 years. As shown in Table 1, 12 staff participated in this study (55\% response rate). Approximately onequarter of staff were relatively new to the institution, having joined in the last two years, and almost one-third had worked at the university for more than 10 years. 


\section{Table 1: Staff Characteristics $(N=12)$}

Item

$N$

$\%$

How long have you worked at UWE?

1-2 years 3

$3-5$ years

6-10 years

More than 10 years

Do you...

Lead a module?

Contribute to teaching on a module?

Supervise student dissertations?

\section{Thematic Analysis}

The overall impression from international students indicated that postgraduate study in the UK was a positive and enjoyable experience. Students were pleased with the quality of education received and the development of new skills. All staff provided examples of considering and responding to international postgraduate student academic needs; however, there were differences in the way that staff perceived and responded to students' personal and social needs. There was a strong sense that staff view international students as an asset to the program, adding a new, broader perspective to the way public health is taught.

Figure l. Thematic analysis
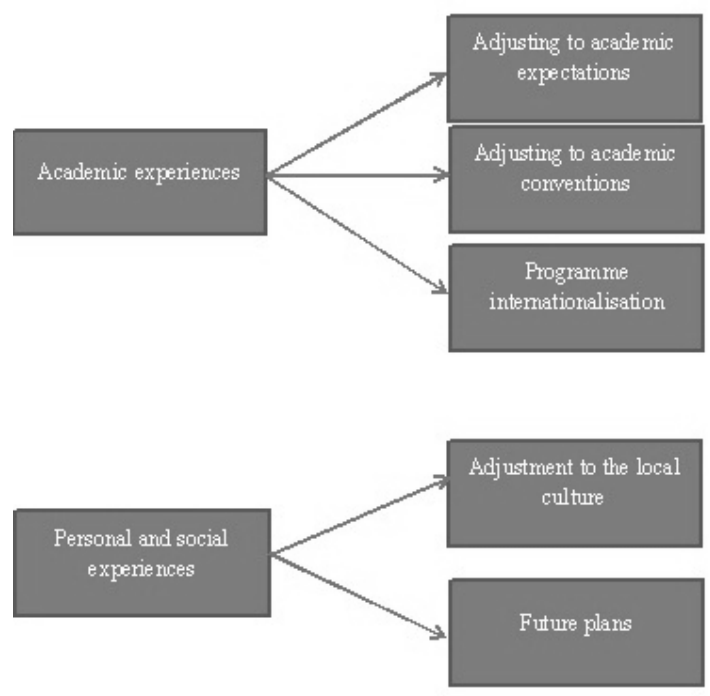
As shown in Figure 1, after initial categorization into two groups: 'Academic experiences' and 'Personal and social experiences', five themes emerged from the data. 'Academic experiences' incorporated: adjusting to academic expectations; adjusting to academic conventions; and, program internationalization. 'Personal and social experiences' included adjusting to the local culture and future plans.

\section{Academic experiences}

Adjusting to academic expectations. A common concern identified by international students was a sense of shock at the way teaching and learning is structured and delivered in the UK. All students revealed that when they began their postgraduate studies they experienced feelings of stress, confusion, and discomfort. In many cases, these feelings of apprehension related to one of the central aspects of the program: critical thinking. In the most part, students reflected that these feelings were influenced by prior educational experiences and different expectations in their home country, with one student commenting:

It has been very different for me because from the background I come from, it's mostly whatever you are taught in class and you have hardly anything to do on your own. When I came here and had to read through articles and read a lot of literature...that was not like before so I had to get used to that.

Other students noted that, as well as facing cultural educational differences, they found it difficult to adjust to studying at postgraduate level.

It's different [studying at postgraduate level] in terms of how they want students to learn. For me, back home, it's all very 'taught', you just learn what you're taught and there's hardly any work to do on your own...this course requires a lot of discipline in terms of managing your own time, apart from just attending the lectures.

Although initial anxiety levels were high among most participants, students also reported feelings of empowerment and pride as they progressed through the program. Almost all students reported perceived improvements in critical thinking skills, ability to work independently, and management of a complex workload.

I think that the critical thinking aspect [of the program] and being able to do things independently [are the most positive outcome of the program]: your own research; finding things out for yourself; and, not being spoon-fed all the information. I think that's been 
really useful. And I think it will be useful when going out to look for work.

Students and staff alike commented on the variety of learning and teaching approaches used to help students adjust to postgraduate level study. For example, there was a strong appreciation for the University Peer Assisted Learning (PALs) program. PALs is an academic support scheme where students are trained in coaching and facilitation skills to support other students in acclimatizing to Higher Education study. Students also identified: small group seminars following lectures interactive question and answer activities designed to engage students, multimedia teaching and learning approaches, and, positive perceptions of the classroom learning environment (described by one participant as 'a safe space' to answer questions in front of peers without fear of embarrassment), as positive program attributes. Such methods were credited with consolidating complex public health topics; in particular, the opportunity for discussion during PALs workshops and small group seminars:

I think the workshops and the seminars specific to some modules have been very helpful. You get to see others' opinions and get to listen to others. That's been very helpful. When you're in smaller groups it really helps. They've been helpful throughout to help us understand stuff from the lecture.

Although many program modules offer workshops or seminars, there was a sense among staff that more work may be required to encourage all international students to engage. One member of staff commented that international students "...need to be shown how to do something, for example, thinking critically, rather than just telling them to do it”. However, another staff member stated: "I expect international students to engage in exactly the same way as home students. I signpost reading in lectures but expect them to identify their own sources as well"; suggestive of a more 'hands-off' approach. One staff member commented that "despite all the direction and information you can give, many still tend to adopt the 'head in the sand' approach until crisis hits”. These differing views suggest that staff may adopt a range approaches to learning and teaching and that there may be inconsistent expectations for students among staff. In light of this, staff may benefit from team discussions on how to effectively engage and manage diverse groups of students. Furthermore, regular monitoring and modernizing of approaches to learning and teaching should be encouraged.

Adjusting to UK academic conventions. The need to adjust to academic conventions was identified by students and staff. For many 
students, despite experience in completing undergraduate qualifications, experience of UK institutional conventions and etiquette was limited. Most students expected a formal classroom atmosphere, where staff and students were distinctly separate groups that interacted on a purely professional basis. All students agreed that their perceptions of the 'student-teacher' relationship changed as the course progressed. However, one student noted:

Something else that still bothers me is calling lecturers by their first name. It still bothers me! I'm just not used to doing that. For me, it's a sign of respect to call them by 'Dr', 'Professor', or whatever it is...It's almost an insult not to do it!

In agreement, when asked to reflect upon academic conventions, most staff recognized that international students may not know how to respond to a UK learning culture and may have unrealistic ideas about the teacher as "an expert" that "may be difficult to approach". Almost all staff commented that they try to overcome such perceptions from the outset, through creating an informal class atmosphere and by clearly communicating expectations to students in lectures and in module handbooks. A key area of concern identified by staff related to international students' writing ability, and specifically, plagiarism among international students. Almost all staff commented that one of the key academic challenges faced by international students is comprehension and interpretation of plagiarism in academic work. In many cases, staff noted that plagiarism can be intentional or unintentional, and it was suggested by one staff member that the teaching team did not provide enough advice and guidance on it. It was also suggested that plagiarism may be a challenging concept to some because "of different cultural educations expectations in their home system". Notably, none of the students identified plagiarism as a potential issue. This finding suggests a discrepancy in student and staff perceptions and identifies an area for development.

Program internationalization. There was broad agreement among students and staff that the program curriculum follows an international perspective to public health. Attempts to 'internationalize' the program and its curriculum were positively received by students, with improvements noted in program content and student rapport. Staff commented on increased incorporation of international examples of public health concepts into their teaching materials, where appropriate, to provide an international context and to aid international student comprehension.

Having a global perspective is useful, whether you intend to bring it back to your home country or whether you intend to stay on in the UK. Having an overall global picture of public health does help. 
However, it was acknowledged that the use of distinct 'international' and 'UK' examples may, in some cases, have had a negative impact on student engagement and rapport. For example, some international students felt that it was difficult to contribute to classes where the focus was UK-based. This was in part due to a lack of knowledge about UK systems but was also related to feelings of intimidation from "knowledgeable" home students, who in many cases were already working in public health roles in the UK.

They [UK home students] probably have more...are better opinionated to say something in class, whereas international students, we're not as aware or knowledgeable about the UK context.

Sometimes it's difficult [to participate] because lots of the home students work in public health, and they're generally a bit more mature, it can feel a bit intimidating because they know things that you just don't know.

Despite this, the majority of students and staff commented on the strong personal rapport that developed between international and UK students during the academic year, although this was seen to vary from module to module. Some staff also identified the use of specific classroom techniques designed to facilitate group interaction, regardless of home country.

This year has seen a particularly good rapport develop. I have encouraged this by arranging my teaching environment in 'tables' rather than 'rows' to encourage discussion between students. Student feedback indicated that this was successful in assisting integration and therefore will be repeated.

The modules that I lead and contribute to the most allow greater engagement with the students and an opportunity to see how they engage and work together. In general, there is a good relationship. However, often the international students do not engage in the workshops as much as I would like.

\section{Personal and social experiences}

Adjusting to cultural adjustments. International students commented on a number of positive and challenging experiences in adjusting to the UK culture. Positive experiences included getting used to different foods, 
making friends with people from all over the world, and learning to interpret conversational English. Some students took part in extracurricular activities (e.g., Christian Union), while others expressed regret at not taking part in non-academic activities. In general, students reported that their perceptions of UK and Bristol culture had improved over time. However, one student reflected:

...It sounds very stupid now that I think of it, but hearing children being quite disrespectful, to me, culturally, that was unacceptable. When I talk to my other international friends, it is always something that we talk about. It's quite shocking to see the way that teenagers or young adults [in the UK] react to situations or the way they talk to adults. That was something I had to get used to and try not to get offended by.

When asked to consider ideas to improve the personal and social experiences of international MSc Public Health students, particularly upon arrival at UWE, staff made a number of suggestions including: implementation of a 'buddy' scheme (i.e., pairing up an international student with a UK student), to learn from similar universities with successful and thriving international student programs, and to encourage students "to get out and explore Bristol and its health issues”. However, one member of staff remarked that:

We should not try to manage them [international students] or intervene too much. Part of the experience is learning to generate your own resources.

This comment highlights discrepancies among staff, and emphasizes the need for the program team to discuss this issue, to ensure that staff are consistent in the support provided. This comment also supports previous research suggesting that international students' personal and social experiences are not high on some staff agendas (Briggs \& Pritchett 2010).

Future plans. Focus group findings revealed that some international students had begun planning for the future. Half of the students expressed interest in staying in the UK after completing their postgraduate qualification, to pursue a career in public health or to study for another health-related qualification. Others were less clear on what they intended to do. One student explained that the program, coupled with her work experience, had encouraged the targeting of a research post: 
I'm currently interning for the [Public Health] research group [based at UWE]. It has helped me to think about qualitative and quantitative research methods that I've learned on the course. It has led me to think that I would really like to get into research. I will see how it goes. I'd definitely like to do work in public health, whether that's research or elsewhere. I'd like to do something in health promotion.

One of the factors associated with unclear future plans was work experience, or a thereof. Students reported that public health jobs in the UK often require a wealth of prior experience. This can be particularly hard to obtain as an international student, as they are less likely to have relevant contacts based within UK public health roles to facilitate work experience. As part of the program, four students completed a voluntary placement scheme based with a public health team in the South West of England. Despite commending the scheme, students felt that they needed a longer period of work experience as a one-week placement would not satisfy the requirements for a public health role.

I would like to stay in public health but I'm finding that most of the jobs that I'm looking at, at the moment, and most people that I speak to on my placement, are looking for experience. Yes, I have nursing experiences, but that's not the experience that they want or the level of experience that they want. So, it's difficult for me to say 'I've got five days' [placement experience], as that's not enough.

It is possible that teaching staff do not have enough of an appreciation of the personal difficulties experienced by students after completing their qualification. When asked to identify challenges faced by students, no staff commented on public health job prospects. This could be a useful area for staff development. Staff responses were more focused on the skills and outcomes associated with the academic program including increased student confidence, improved critical thinking skills, improved communication and presentation skills, and development of skills in qualitative and quantitative research methodologies.

\section{DISCUSSION AND CONCLUSIONS}

The findings presented here add to the evidence base on the academic, personal and social experiences of postgraduate international students studying at UK universities. The key contributions of this research lie in the comparison of student and staff perceptions of the international student experience, an area which is relatively unexplored to date. The study also 
considers the views and experiences of a diverse range of international students, adding a new perspective to the literature which is chiefly concerned with the experiences of Asian students (Institute of International Education, 2014).

The finding that international students may find it difficult to adjust to academic expectations and conventions is widely supported by the literature (Bamford et al., 2002; Durkin, 2003; Kiley, 2003; Kingston \& Forland, 2008; Oliver, 2008; Wang \& Shan, 2006). However, despite their initial difficulties, students in this study were broadly positive about their experiences and identified numerous improvements in their academic skill set; a finding also reported by Hills and Thorn (2005). Students and staff alike commented on the techniques used to assist international students in adjusting to life at a UK university; for example, the use of interactive seminars allowing students to actively participate and engage in small groups. Interactive approaches to teaching and learning are encouraged in training guidance by public health specialists (Association of Schools of Public Health, 2004; Kim, Brown, Fields \& Stichler, 2009) and such techniques have been shown to facilitate the retention of new materials (Nouri \& Shahid, 2005), increase learner interest in the topic being covered (Steinert \& Snell, 1999), and overcome the issue of large class sizes (Light, 2001; Maringe \& Sing, 2014).

The finding that international students expected to develop a purely professional relationship with academic staff during their time at university is not unique to this study and has been reported elsewhere (Durkin et al., 2003; Wang \& Shan, 2006). However, it should be noted that such anxieties are also commonly reported among native UK students (Kingston \& Forland, 2008). Although the 'student-teacher' relationship did not meet students' pre-conceived ideas, the development of a positive rapport was seen to be a positive experience, with students reporting that they felt confident to approach staff with questions or concerns. This finding is important in light of evidence to suggest that positive student-teacher rapport is associated with improved communication (Heffernan, Morrison, Sweeney \& Jarrett, 2009), participation (Frisby \& Martin, 2010), and student motivation (Wilson, Ryan \& Pugh, 2010).

One of the main findings from this research highlighted a discrepancy between student and staff perceptions of students' writing ability and understanding of plagiarism. Staff perceived plagiarism as a key area for concern, reporting that some students fail to fully interpret or comprehend plagiarism in their work. It has been suggested that students should face tougher penalties for plagiarized work (White, 1993), however, it has also been suggested that the focus of university staff should be on prevention (Park, 2004). Park proposes an institutional framework where students are given an opportunity to learn from their mistakes and receive 
specific support and guidance to help them progress. Previous research with university staff has also identified this as a pertinent issue (Kingston \& Forland, 2008; O’Reilly et al., 2013; Wang \& Shan, 2006) and this suggests that more work may be required to enhance student awareness, understanding and compliance with university regulations. Therefore, encouraging students and staff to engage with such a framework may help to tackle some of the misconceptions identified in this study.

This study also highlighted the importance of considering international students' personal and social experiences and supports the assertion that the student experience may be affected by more than academic factors alone (Bamford et al., 2002; Edwards \& Ran, 2006). Broadly speaking, students reported positive personal and social experiences associated with their time in the UK, however, all felt that they needed to adjust to UK culture in some way. For example, some students attended extracurricular activities and developed networks beyond the academic setting. This has been shown to help students integrate into a new culture (Carter, 2010; Spencer-Oatey, Dauber \& Williams, 2014).

Staff responses suggested that staff are aware of the importance of international students' personal and social experiences as well as their academic experiences, and it was interesting to note the numerous suggestions for improving such experiences from the outset. For example, one staff member suggested pairing an international student with a UK student. Similar schemes are already in use at other universities and may help to overcome initial feelings of isolation and loneliness frequently experienced by international students (Bamford et al., 2002; Bamford, 2008; Edwards \& Ran, 2006). However, despite staff interest in international students' personal and social wellbeing, there was a sense among some that students themselves are responsible for their experiences beyond academic teaching, a finding reported elsewhere (Briggs \& Pritchett, 2010; Miles and Leinster, 2009). These inconsistencies within the programme team suggest that staff may benefit from further discussion of their role in students' personal and social experiences during their time at university.

In addition to making cultural adjustments, it was identified that students were at various stages of planning for their future. The majority of students expressed an interest in remaining in the UK to pursue further study or a career in public health. Students recognized the importance of obtaining work experience to increase their chances in the job market following graduation (High Flyers Research Limited, 2013), with the majority of students in this study actively seeking experience from a variety of organizations. However, there was a sense that some of the work experience obtained was insufficient to meet public health job specifications. For example, placements arranged with local public health teams were perceived to be enjoyable and beneficial, but were too short in duration. From a staff 
perspective, work experience opportunities were not identified as an important aspect of the international student experience. This is suggestive of a discrepancy in student and staff perceptions and highlights the need for staff to respond to student responses and to consider ways to improve the opportunities offered to students.

It is important to recognize that the findings from this study should not be generalized to the wider international study body as the sample was relatively small and the focus was specific to postgraduate study at one UK University. The majority of international students in the study were aged from 22 to 27, with one student aged 34 years. This has important implications for how these findings are interpreted. Postgraduate courses in the UK recruit students of all ages and it is possible that older students' perspectives are not well-represented by this study; an area that could be further developed in future research. The use of an open-ended survey with staff was pragmatic in that it enabled staff to take part at their convenience, as opposed to attending an interview or focus group which may have proved problematic during the busy academic year. However, future research may consider exploring staff perceptions using more traditional qualitative methods to elicit in-depth responses and reflections which may be difficult to articulate via open-ended survey items.

\section{IMPLICATIONS}

Despite its limitations, this study identifies numerous recommendations as to how findings might be used to enhance the international postgraduate student experience:

- University staff should continue to work to manage international postgraduate student expectations and support their needs, notably in relation to academic workload, approaches to teaching and learning and academic conventions (e.g., plagiarism).

- University staff should continue to internationalize the program curriculum, to aid international student comprehension of public health concepts and to provide an opportunity for discussion among students from diverse backgrounds.

- University staff should adopt a range of teaching and learning approaches, ensuring opportunities for interaction, allowing for active international student participation and engagement with the materials. Notably, staff should continue to incorporate small group seminar activities into module timetables, where possible.

- University staff may wish to further consider their role in supporting international postgraduate student personal and social needs. For example, staff may encourage students to engage with extracurricular 
activities, which may, in turn, have a positive impact upon their wider university experience.

- University staff may wish to consider how to enhance international postgraduate student employability beyond academic qualifications, through further development of the placement scheme and signposting to potential work experience opportunities.

\section{REFERENCES}

Associations of Schools of Public Health. (2004). Demonstrating excellence in practice-based teaching for public health. U.S. Department of Health: Association of Schools of Public Health.

Bamford, J. (2008). Strategies for the improvement of international students' academic and cultural experiences of studying in the UK. Available from: https://www.heacademy.ac.uk/sites/default/files/e2_strategies_for_improvement.pdf

Bamford, J., Marr, T., Pheiffer, G., \& Weber-Newth, I. (2002). Some features of the cultural and educational experience and expectations of the international postgraduate students in the UK. Proceedings of the BEST Conference. Edinburgh, Scotland.

Bean, J. C. (2001). Engaging ideas: The professor's guide to integrating writing, critical thinking, and active learning in the classroom. San Francisco, CA: Jossey-Bass.

Braun, V., \& Clark, V. (2006). Using thematic analysis in psychology. Qual Res Psych, 3(2), 77-101.

Briggs, N., \& Pritchett, N. (2010). A comparison of staff perceptions and student experiences of issues associated with university study. Journal of Learning Development in Higher Education, 2, 1-21.

Carter, P.L. (2010). Race and cultural flexibility among students in different multiracial schools. Teachers College Record, 112 (6), 1529-1574.

Department for Business and Innovation Skills. (2011). Estimating the value to the UK of education exports. Available from:

https://www.gov.uk/government/publications/education-exports-estimating-their-valueto-the-uk

Durkin, K. (2003). Challenges Chinese students face in adapting to academic expectations and teaching/learning styles of UK Masters courses, and how cross-cultural understanding and adequate support might aid them to adapt. Available from: http://www.britishcouncil.cn/en/study-uk/scholarships

Edwards, V., \& Ran, A. (2006). Meeting the needs of Chinese students in British higher education. Available from https://blogs.shu.ac.uk/internationalnetwork/files/2013/07/MeetingTheNeeds.pdf

Ehrenberg, R.G., Brewer, D.J., Gamoran, A., \& Willms, J.D. (2001). Class size and student achievement. Psychological Science in the Public Interest, 2(1), 1-30).

Frisby, B.N., \& Martin, M.M. (2010). Instructor-student and student-student rapport in the classroom. Communication Education, 59, 146-164.

Healey, N. (2008). Is higher education 'internationalising'? Higher Education, 31(3), 325340.

High Flyers Research Limited. (2013). The UK Graduate Careers Survey. Available from: http://www.lboro.ac.uk/service/careers/downloads/HFPresentation.pdf

Higher Education Funding Council for England [HEFCE]. (2010). The higher education workforce framework 2010: overview report. Bristol: HEFCE.

Higher Education Statistics Agency [HESA]. (2014). Students in Higher Education. Available from: 
https://www.hesa.ac.uk/index.php?option=com_pubs\&Itemid=\&task=show_year\&pubI $\mathrm{d}=1$ \&versionId $=25 \&$ yearId $=312$

Heffernan, T., Morrison, M., Sweeney, A., \& Jarrett, D. (2009). Personal attributes of effective lecturers: The importance of dynamism, communication, rapport and applied knowledge. International Journal of Management Education, 8, 13-37.

Hills, S., \& Thorn, V. (2005). Crossing a multicultural divide: Teaching business strategy to students from culturally mixed backgrounds. Journal of Studies in International Education, 9(4), 316-336.

Hoyt, D., \& Perera, S. (2000). Validity of the IDEA student ratings of instruction system: An update. IDEA research report, 2.

Institute of International Education. (2014). Open Doors Data. International Students: Places of Origin. Available from: http://www.iie.org/Research-and-Publications/OpenDoors/Data/International-Students/All-Places-of-Origin

Kiley, M. (2003). Conserver, strategist or transformer: The experience of postgraduate student sojourners. Teaching in Higher Education, 8(3), 345-356.

Kim, S.C., Brown, C.E., Fields, W., \& Stichler, J.F. (2009). Evidence-based practice-focused interactive teaching strategy: A controlled study. Journal of Advanced Nursing, 65, 1218-1227.

Kingston, E., \& Forland, H. (2008). Bridging the gap in expectations between international students and academic staff. Journal of Studies in International Education, 129(2), 204221.

Li, J., Wang., \& Xiao, F. (2014). East Asian International Students and Psychological WellBeing: A Systematic Review. Journal of International Students, 4(4), 301-313.

Light, R.J. (2001). Making the most of college: Students speak their minds. Cambridge, MA: Harvard University Press.

Lillyman, S., \& Bennett, C. (2014). Providing a positive learning experience for international students at UK universities: A literature review. Journal of Research in International Education, 13(1), 63-75.

Maringe, F., \& Sing, N. (2014). Teaching large classes in an increasingly internationalising higher education environment: pedagogical, quality and equity issues. Higher Education, 67, 761-782.

Miles, S., \& Leinster, S.J. (2009). Comparing staff and student perceptions of the student experience at a new medical school. Medical Teacher, 31, 539-546.

Nouri, H., \& Shahid, A. (2005). The effect of PowerPoint presentation on student's learning and attitudes. Global Perspectives on Accounting Education, 2, 53-73.

Oliver, R. (2008). Engaging the first year students using a Web-supported inquiry-based learning setting. Higher Education, 55(3), 285-301.

O’Reilly, A., Hickey, T., \& Ryan, D. (2013). Higher education professionals' perspective on international student experiences of life and learning in Ireland: A qualitative study. Irish Education Studies, 32(3), 355-375.

Organisation for Economic Co-operation and Development (OECD). (2008). Education at a Glance: OECD Indicators 2006. Paris: OECD.

Ozga, J., \& Sukhnandan, L. (1998). Undergraduate non-completion: developing an explanatory model. Higher Education Quarterly, 52(3), 316-333.

Park, C. (2004). Rebels without a clause: towards an institutional framework for dealing with plagiarism by students. Journal of Further and Higher Education, 28(3), 291-306.

Russell, J., Rosenthal, D., \& Thomson, G. (2010). The international student experience: Three styles of adaptation. Higher Education, 60(2), 235-249.

Sawir, E. (2005). Language difficulties of international students in Australia: The effects of prior learning experience. International Education Journal, 6(5), 567-580.

Seo, S., \& Koro-Ljungberg, M. (2005). A hermeneutical study of older Korean students' experiences in American higher education: From Confucianism to western educational values. Journal of Studies in International Education, 9(2), 164-187. 
Smith, R.A., \& Khawaja, N.G. (2011). A review of acculturation experiences of international students. International Journal of Intercultural Relations, 35, 699-713.

Spencer-Oatey, H., Dauber, D., \& Williams, S. (2014). Promoting integration on campus: Principles, practice, and issues for further exploration. UKCISA.

Steinert, Y., \& Snell, L.S. (1999). Interactive learning: strategies for increasing participation in large group presentations. Medical Teacher, 21, 37-42.

Tight, M. (2004). Research into higher education: An a-theoretical community of practice? Higher Education Research and Development, 23(4), 395-411.

Turcic, S. (2008). Needs Assessment of International Students in the City of Sydney: Project Report.

Available

from:

http://www.cityofsydney.nsw.gov.au/_data/assets/pdf_file/0004/71428/NeedsAssessment-International-Students.pdf

UK Council for International Student Affairs (UKCHISA). (2015). International student statistics: UK higher education. Available from: http://www.ukcisa.org.uk/Info-foruniversities-colleges--schools/Policy-research--statistics/Research-statistics/International-students-in-UK-HE/

Wang, J. (2012). Culturally inclusive practice: a case study of an international student support initiative at an Australian university. Asian Social Science, 8(4), 68-76.

Wang, T., \& Shan, X. (2006). A qualitative study on Chinese postgraduate students' learning experiences in Australia: Proceedings of the International Education Research Conference. Adelaide, Australia, 26-30 November.

Ward, C., Bochner, S., \& Furnham, A. (2001). The psychology of culture shock. Hove, East Sussex: Routledge.

White, E.M. (1993). Too many campuses want to sweep student plagiarism under the rug. Chronicle of Higher Education, 39(25), 44.

Wilson, J.H., Ryan, R.G., \& Pugh, J.L. (2010). Professor-student rapport predicts student outcomes. Teaching of Psychology, 37, 246-251.

EMMA BIRD is a Senior Lecturer in Public Health at the University of the West of England, Bristol, UK. E-mail: emma.bird@uwe.ac.uk 